\author{
Abstracta Iranica \\ Abstracta Iranica Revue bibliographique pour le domaine irano-aryen \\ Volume 34-35-36 | 2017 \\ Comptes rendus des publications de 2011-2013
}

\title{
Philippe Gignoux, Christelle Jullien, Florence Jullien (textes réunis par). Trésors d'Orient. Mélanges offerts à Rika Gyselen
}

Philip Huyse

\section{(2) OpenEdition \\ Journals}

Édition électronique

URL : http://journals.openedition.org/abstractairanica/41941

DOI : 10.4000/abstractairanica.41941

ISSN : 1961-960X

Éditeur :

CNRS (UMR 7528 Mondes iraniens et indiens), Éditions de l'IFRI

Référence électronique

Philip Huyse, «Philippe Gignoux, Christelle Jullien, Florence Jullien (textes réunis par). Trésors d'Orient Mélanges offerts à Rika Gyselen », Abstracta Iranica [En ligne], Volume 34-35-36 | 2017, document 2, mis en ligne le 30 juillet 2017, consulté le 30 septembre 2020. URL : http://journals.openedition.org/ abstractairanica/41941; DOI : https://doi.org/10.4000/abstractairanica.41941

Ce document a été généré automatiquement le 30 septembre 2020.

Tous droits réservés 


\title{
Philippe Gignoux, Christelle Jullien, Florence Jullien (textes réunis par). Trésors d'Orient. Mélanges offerts à Rika Gyselen
}

\author{
Philip Huyse
}

\section{RÉFÉRENCE}

Philippe Gignoux, Christelle Jullien, Florence Jullien (textes réunis par). Trésors d'Orient. Mélanges offerts à Rika Gyselen. Paris, Association pour l'Avancement des Etudes Iraniennes, 2009, 409 p. (Studia Iranica, Cahier 42)

1 Bien que la production scientifique de Rika Gyselen s'étende sur près de quarante ans, c'est surtout sur la dernière décennie qu'elle a eu à son actif une production tout à fait exceptionnelle (la moitié parmi la vingtaine de ses monographies a vu le jour depuis l'an 2000), qui ont souvent bouleversé nos connaissances dans les domaines de la sigillographie et de la numismatique sassanides ainsi que du monnayage arabosassanide. Comme le souligne avec insistance Philippe Gignoux dans son " Avantpropos » (p. 5-8), Rika Gyselen a tout au long de sa carrière fait preuve de ses " remarquables talents d'éditrice " (p. 8), à la fois comme co-directrice de la série " Cahiers de Studia Iranica " (avec plus de quarante volumes parus aujourd'hui) et comme directrice de la série « Res Orientales ", qu'elle avait elle-même fondée en 1989. Les lecteurs du volume sauront par ailleurs gré aux éditeurs d'avoir inclus la " Bibliographie » (p. 9-18) complète des travaux de Rika Gyselen dans ce riche recueil en son honneur.

Le volume consiste au total des vingt-deux contributions suivantes : Michael Alram, «A new drachm of Ardashir I » (p. 21-26). Maryse Blet-Lemarquand, « Premières frappes locales de l'Inde du Nord-Ouest : l'apport des analyses élémentaires»(p. 27-38). 
Osmund Bopearachchi, « Premières frappes locales de l'Inde du Nord-Ouest : nouvelles données » (p. 39-50). Pierfrancesco Callieri, «Bishapur: the palace and the town » (p. 51-65). Nina Garsoïan, « La politique arménienne des Sassanides » (p. 67-79). Philippe Gignoux, «Les documents éonomiques de Xwarēn » (p. 81-102). Frantz Grenet, « Le rituel funéraire zoroastrien du sedra dans l'imagerie sogdienne » (p. 103-11). Florence Hellot-Bellier, " Amédée Querry, Arthur de Gobineau et la Perse (1855-1872) » (p. 113-43). Philip Huyse, " Die königliche Erbfolge bei den Sasaniden » (p. 145-57). Florence Jullien, " La chronique du Ḥūzistān. Une page d'histoire sassanide » (p. 159-86). Christelle Jullien, «Quelques événements tirés d'ecclesiastikē et de cosmotikē » (p. 187-205). Gilbert Lazard, " Hâfez d'humeur allègre » (p. 207-10). Judith A. Lerner, Ahmad Saeedi, Nicholas Sims-Williams, "The Bactrian Sealings in the A. Saeedi Collection (London)» (p. 211-35). Malek Iradj Mochiri, « Une monnaie de Khusraw I de l'atelier de Samarcande » (p. 237-44). Karin Mosig-Walburg, "Yazdgerd I. 'der Sünder' » (p. 245-68). Antonio Panaino, «Anche 'il migliore' si arrabbia. A proposito di Y. 19, 15 » (p. 269-81). Parvaneh Pourshariati, "The Mihrāns and the Articulation of Islamic Dogma: a Preliminary Prosopographical Analysis » (p. 283-315). Francis Richard, « Les missions catholiques à Isfahan du XVIIème au XIXème siècle : la diplomatie au service de l'apostolat » (p. 317-34). Michel Tardieu, « Les localités mandéennes de Jean-Baptiste Tavernier » (p. 335-58). François Thierry, « Cinq notes sur Shi Siming (759-761)» (p. 359-78). Dieter Weber, « Zu den Brotrationen in den Pahlavi-Ostraka » (p. 379-89). Joseph [sic] Wiesehöfer, « Kawad, Khusro I and the Mazdakites: a New Proposal » (p. 391-409).

\section{AUTEURS}

PHILIP HUYSE

EPHE 